\title{
Research Questionnaire on Perception of Seafarers about Oral Hygiene and Oral Dietary Habits
}

\author{
${ }^{1}$ Syed Sarosh Mahdi, ${ }^{2}$ Maurizio Mancini, ${ }^{3}$ Fabio Sibilio, ${ }^{4}$ Francesco Amenta
}

\begin{abstract}
Objectives: Dental problems are among the main concerns of seafarers and a relevant cause of medical consultations aboard international vessels. Seafarers may neglect their oral hygiene during long voyages and are known for their excessive intake of beverages or unhealthy food which contains copious amounts of fermentable carbohydrates and sugars, which are prime risk factors of dental caries. Majority of studies done on oral health status of seafarers are dated. This paper presents a questionnaire developed by Centro Internazionale Radio Medico (CIRM), the Italian Telemedical Maritime Assistance Service (TMAS) to investigate the oral hygiene condition of seafarers and to assess their awareness and sensitivity on this pertinent health problem.
\end{abstract}

Methodology: A questionnaire including 26 questions covering general information about the subject, including denture status, smoking, drinking and eating habits, general appearance of gingiva, oral muscosa and lips was developed. The research questionnaire was created to assess the oral health situation of Seafarers on board various ships around the world. The questionnaire was forwarded to different ships using the platform of Centro Internationzionale Radio Medico in Rome. Twenty-six questions on various oral hygiene indicators were part of the questionnaire. Captains of the ship were requested to summarize the results on a summary sheet provided by CIRM. CIRM started out sending questionnaire at the end of June 6 and the project concluded in October.

Results: In the 3 months of the survey, CIRM assisted 1,198 ships. All these ships were requested to take part in the research survey. CIRM received positive response from 65 vessels. The rate of return was $5.4 \%$. Two thousand and sixty seamen filled the questionnaire. No difficulty was reported by ship's captains in summarizing the results of the survey.

Conclusion: The findings of the research will be presented in an original research article after completion of data analysis.

\footnotetext{
${ }^{1} \mathrm{PhD}$ Scholar, ${ }^{2}$ Dental Practitioner, ${ }^{3}$ Administrative Assistant ${ }^{4}$ Professor

${ }^{1}$ Telemedicine and Telepharmacy Centre, University of Camerino Camerino, Italy

${ }^{2,3}$ Research Department, International Radio Medical Centre Rome, Italy

${ }^{4}$ Telemedicine and Telepharmacy Centre, University of Camerino, Camerino; Research Department, International Radio Medical Centre, Rome, Italy
}

Corresponding Author: Francesco Amenta, Professor Medicine and Health Product Sciences, Clinical Research Center, Department of Telemedicine and Telepharmacy, Via Madonna delle Carceri, Camerino, Italy, Phone: +39 0737403311 403326, e-mail: famenta@hotmail.com
Captains of the ships who took part in the project were awarded certificates of appreciation for their effort. The results of the project will be useful in future policy initiatives regarding oral healthcare of seafarers.

Keywords: Dental health, Dental hygiene promotion, Oral habits, Research questionnaire, Seafarers, Ship.

How to cite this article: Mahdi SS, Mancini M, Sibilio F, Amenta F. Research Questionnaire on Perception of Seafarers about Oral Hygiene and Oral Dietary Habits. World J Dent 2015;6(1):1-4

\section{Source of support: Nil}

Conflict of interest: None

\section{INTRODUCTION}

Seafarers represent a vulnerable group as they are isolated during long sea voyages. Seafarers are susceptible the use of excessive amounts of snacks, they also consume excessive amounts of tea, coffee and beverages due to their odd working hours and unique lifestyle, most of these dietary substances contain fermentable carbohydrates and sugars. Food rich in fermentable carbohydrates and sugar is considered to be prime risk factors of dental caries and associated dental diseases. ${ }^{1,2}$ This is the reason why Centro Internazionale Radio Medico (CIRM) decided to create this questionnaire on oral health habits of seafarers. Centro Internazionale Radio Medico was established in 1935 with the aim of giving free radio medical advice to ships of all nationalities navigating on international waters. The center has its headquarters in Rome, and its basic medical services are completely free of charge. Requests for medical advice reaching CIRM are handled by doctors who are on 24-hour duty. ${ }^{3}$

Dental fitness of seafarers is deemed essential by International Labour Organization (ILO) and World Health Organization (WHO). ${ }^{4}$ One study has demonstrated that seafarers neglect oral hygiene during long voyages. ${ }^{5}$ Seafarers have been widely reported for their unusually high intake of nicotine which is probably related to occupational stress and odd duty hours. Nicotine is considered as the most important preventable risk factor associated with periodontal disease. ${ }^{6}$ The Danish Radiomedical service in its annual report 2010, which covered over 1,300 consultations, reported that dental problems $(8.1 \%)$ were among the four most reported concerns of seafarers. ${ }^{7}$ One study mentioned that on 
merchant navy vessels with a complete lack of oral care facilities the causes of consultations for dental problems at foreign ports can be as high as $67 \% .^{8}$ A survey held in 1995 reported that only 19 countries provide dedicated oral health services for seafarers. ${ }^{9}$

That is why more research is required to investigate the oral hygiene status of seafarers and to assess their awareness and sensitivity to the problem.

\section{METHODOLOGY}

A research questionnaire was prepared along with a summary of all the questions. The questionnaire was designed in English and Italian languages. A summary of all the questions on the questionnaire was also created for the captain of each ship to save time and paper work. Two document files were created and sent via e-mail to various merchant navy ships, which were in contact with CIRM, the Italian Telemedical Maritime Assistance Service (TMAS). In the 3 months, CIRM conducted this survey, 1198 ships were contacted, 65 ships replied to CIRM's request and took part in the research project by returning the filled questionnaire and the summary. The first document contained the actual questionnaire. The other document is a summary of the list of responses to the 26 questions on the questionnaire.

Letters were also written to various shipping companies asking them to collaborate with CIRM in this survey and to distribute the questionnaire among various ships in their fleet, the summary and a note of CIRM president introducing the initiative and explaining how to fill-in the questionnaire was also forwarded. Italian shipping companies with a long history of association with CIRM were contacted. All ships asking for medical advice to CIRM from 1 July 2014 till October 2014 were invited to participate in the research survey. Those interested in contributing to the initiative were required to send an e-mail in response after which questionnaires and instructions were sent to the participating ship. The captain of each ship was informed that he can fill the summarized chart after getting responses of all the seamen on board. In case, the captain had any queries he was requested to contact via e-mail the CIRM dental specialist in charge of the project, Dr Syed Sarosh Mahdi.

To appreciate the efforts of the captain CIRM has decided to award certificates and appreciation letters from the CIRM. Ships collaborating to the initiative also received a complimentary copy of the book oral hygiene and its maintenance, specifically developed for increasing the awareness of seafarers to the problem. ${ }^{15}$

\section{RESULTS}

In 3 months of the survey, CIRM assisted 1,198 ships and 65 ships returned the filled questionnaire back to
CIRM, with a rate of return averaging around $5.42 \%$. Two thousand and sixty seamen filled the questionnaire on board these 65 ships. No difficulties were reported by ship's captains in summarizing the results of the survey.

The 26 questions covered the four areas mentioned below: (i) general information about the subject, (ii) denture status, (iii) smoking, drinking and eating habits and (iv) actual mouth, gum and lips condition. The questionnaire, rate of return and other statistics can be found at the end of the manuscript in Tables 1 and 2.

\section{DISCUSSION}

Seafarers lead extremely stressful lives due to social isolation and other occupational challenges and their oral hygiene on board, generally remains neglected. ${ }^{10,11}$ A detailed review of the literature has revealed that the oral hygiene problems and habits of seafarers have not been studied extensively and only a few investigations have been carried out on oral health situation of seafarers. ${ }^{12}$ Another problem that was very evident after going through the literature on the topic is the fact that most of the studies done on oral health of seafarers are dated. ${ }^{13,14}$

This is the reason why CIRM decided to create this questionnaire on oral health habits of seafarers. CIRM was established in 1935 with the aim of giving free radio medical advice to ships of all nationalities navigating on international waters. The center has its headquarters in Rome, and its basic medical services are completely free of charge. Requests for medical advice reaching CIRM are handled by doctors who are on 24 hours duty. Centro Internazionale Radio Medico is now planning to extend its facilities to include a dental assistance and awareness program for seafarers navigating international waters. The program envisages complete dental evaluation of seafarers onboard and a dental checkup before they board the ship. The program could drastically bring down the number of dental-related emergencies onboard ships and improve oral hygiene and dental health of seafarers.

As a starting point of this new project, addressing the problems of oral and dental health of seafarers, this research questionnaire presented above here has been developed. The questionnaire was filled by seaman of all ranks and has provided relevant insight into the dental health situation of seafarers. We are still in the process of date analysis, the complete results will help us to understand the oral hygiene status of seafarers which in

Table 1: Details regarding number of ships contacted, took part in the survey and total number of sailors surveyed

\begin{tabular}{llll}
\hline $\begin{array}{l}\text { Ships } \\
\text { contacted }\end{array}$ & $\begin{array}{l}\text { Took part } \\
\text { in survey }\end{array}$ & $\begin{array}{l}\text { No. of } \\
\text { seafarers }\end{array}$ & $\begin{array}{l}\text { Rate of } \\
\text { return }\end{array}$ \\
\hline 1198 & 65 & 2060 & $5.4 \%$ \\
\hline
\end{tabular}


Table 2: The complete questionnaire given to each crew member is reported below

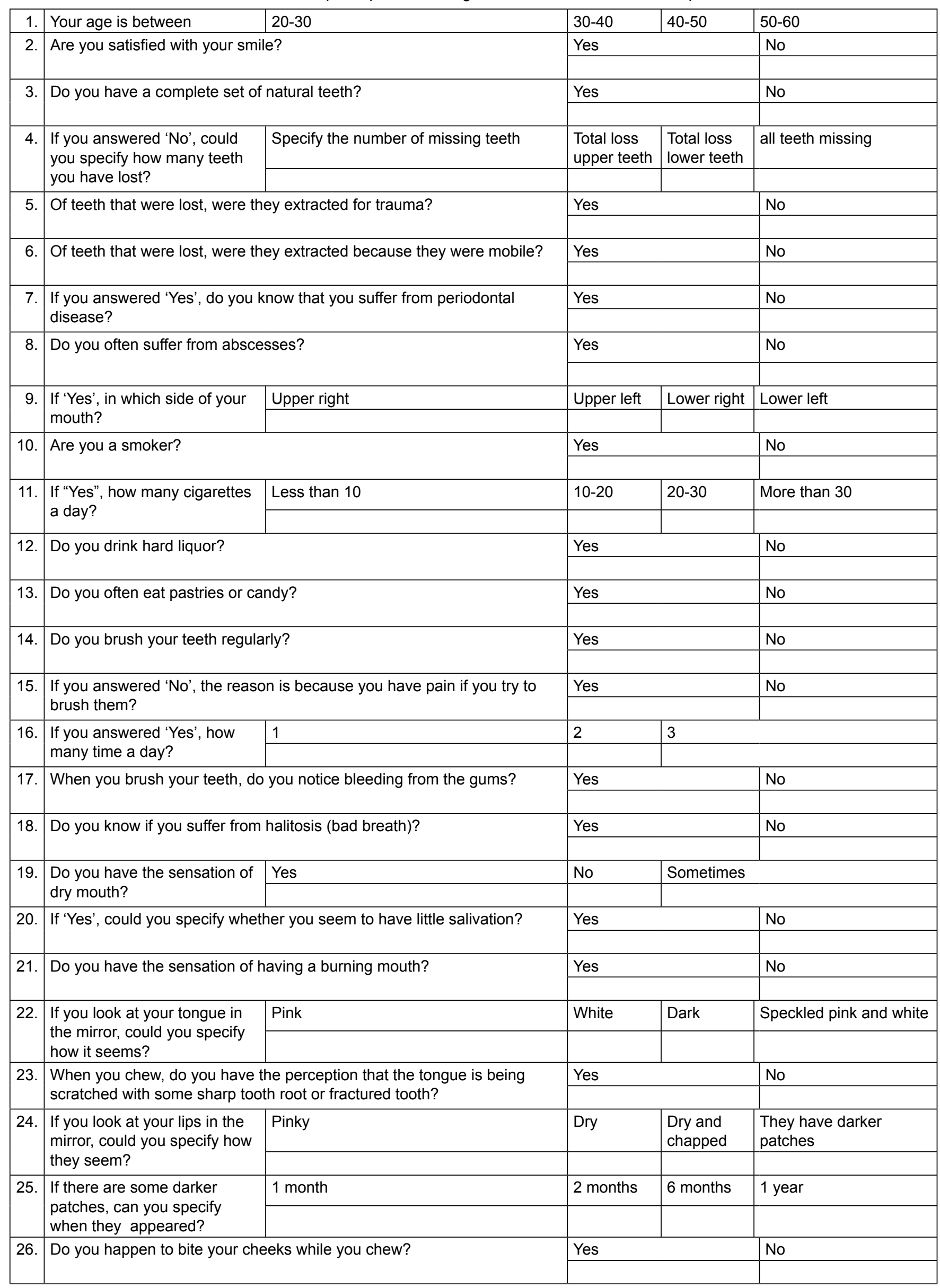


The form provided to ship captains participating to the survey for summarizing the results of the questionnaire is reported below:

\begin{tabular}{|l|l|l|l|l|l|}
\hline Question no. & Interviewed no. 1 & Interviewed no. 2 & Interviewed no. 3 & Interviewed no. 4 & Etc. \\
\hline 1 & & & & & \\
\hline 2 & & & & & \\
\hline 3 & & & & & \\
\hline 4 & & & & & \\
\hline 5 & & & & & \\
\hline 6 & & & & & \\
\hline 7 & & & & & \\
\hline 8 & & & & & \\
\hline Etc. & & & & & \\
\hline
\end{tabular}

Provision of this summary involving the collaboration of the captain allowed to get results of the survey easily, without the need of mailing to the center proposing the questionnaire a lot of papers shipped from the first port of call

turn will help us in understanding their dental condition. The results will be used to design a project to promote dental health among seafarers. An advantage of a simple questionnaire like the one proposed is that it can be filled-in on board and, therefore, reflects awareness of dental health problems perceived by seafarers when they are at sea.

\section{CONCLUSION}

We are proposing this questionnaire as an instrument to understand the layman perception of seafarers about their oral health condition and problems associated with maintaining proper oral hygiene during long sea voyages. The results of the survey can be used in the bigger context of providing quality dental care to seafarers and improve their awareness on this important topic.

\section{REFERENCES}

1. Amenta F, Dauri A. Activities of the International Radio Medical Centre (CIRM) in Rome during the last five years (1996-2000). Centro Internazionale Radio Medico. International Maritime Health 2001;52:68-73.

2. Holttinen T, Murtomaa H, Pentti J, Alvesalo I. Utilization of Dental services by Finnish seaman. Acta Odontol Scand 1995;53(3):275-278.

3. Mausberg R, Hornecker E, Rellermeir I. Fallstudie zur Mundgesundheit auf einem Schiff Der Bundesmarine. Wehrmedizinische Monatsschrift 2000;44(5):65-70.
4. ILO/WHO. Guidelines for conducting Pre-Sea and Periodic Medical Fitness Examinations for Seafarers; 1997. Cited on: 0210-2014. Available at: www.ilo.org/public/english/dialogue/ sector/techmeet/ilowho97/index.htm

5. Dahl E. Sick leave aboard-a one-year descriptive study among crew on a passenger ship. Int Marit Health 2005;56 (1-4):5-16.

6. LG Do, Spencer AJ, Dost F, Farah CS. Oral mucosal lesions: findings from the Australian National Survey of Adult Oral Health. Australian Dental Journal 2014;59:(10).1111/ adj.2014.59.issue-1, 114-112.

7. Radio Medical Danmark. Annual Report 2010. Esbjerg; 2011.

8. Tomaszunas S. The work of ship's doctors of Polish Ocean Lines. Bull Inst Marit Trop Med Gdynia 1985;36:51-58.

9. Saarni UM, Saarni H, Holttinen T, Fellman MT. Seafarer's dental health—an international problem? In: Third International Symposium on Maritime Health; 1995, 1997; Baltimore, MD: Maritime Institute of Technology and Graduate Studies; 1995. p. 139-142.

10. Mausberg R, Hornecker E, Rellermeier I. Fallstudie zur Mundgesundheit auf einem Schiff der Bundesmarine. Wehrmedizinische Monatsschrift 2000;44(4):65-70.

11. Deutsch WM. Dental Events during periods of isolation in the US submarine force. Mil Med 2008;173(10):29-37.

12. AJ Sobotta B, Reiber T, Nitschke I. Oral health of seafarers-a review. Int Marit Health 2011;62(5):8-16.

13. Ellis FN. Dental appointment problems at Sea. US Armed Forces Med J 1954;5:721-723.

14. Hall FL. General Practice organization in the Royal Navy. Br Dent J 1972;132(4):321-324.

15. Amenta F, Dauri A, Rizzo A. Organization and activities of the International Radio Medical Centre (CIRM). J Telemedicine and Telecare 1996;2(3):125-131. 